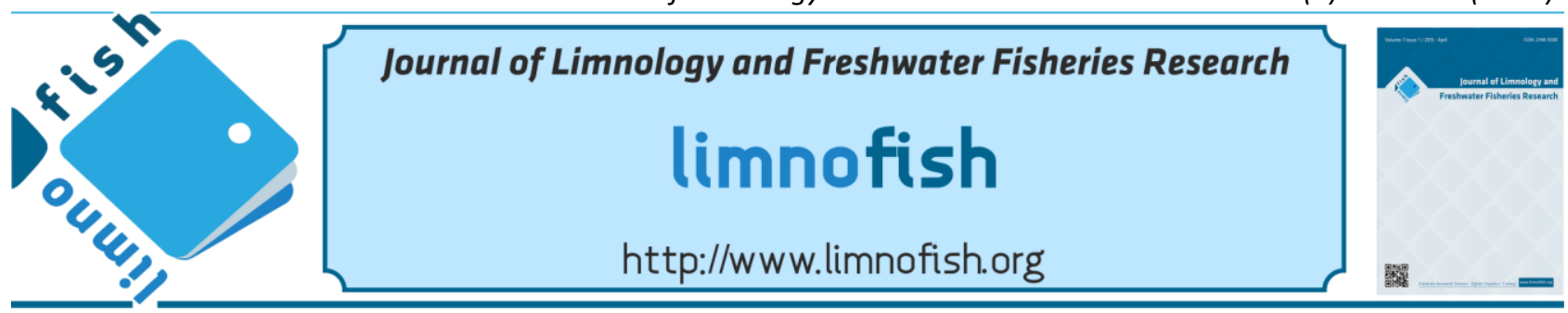

\title{
Landmark-Based Morphological Differences Among the Exotic Rhinogobius lindbergi and Its Two Sympatric Gobies (Actinopterygii: Perciformes: Gobiidae) in Sefid River, in the Southern Caspian Sea Basin
}

\author{
Adeleh HEIDARI ${ }^{1,2}$ (D), Hamed MOUSAVI-SABET*1,2 (D), Masoud SATTARI ${ }^{1,2}$ (D), Mohammad-Sadegh \\ ALAVI-YEGANEH ${ }^{3}$ \\ ${ }^{1}$ Department of Fisheries Sciences, Faculty of Natural Resources, University of Guilan, Sowmeh Sara, P.O. Box 1144, Guilan, \\ Iran \\ ${ }^{2}$ The Caspian Sea Basin Research Center, University of Guilan, Rasht, Iran \\ ${ }^{3}$ Department of Fisheries, Faculty of natural Resources, Tarbiat Modares University, Nour, Iran
}

\section{A B STRACT}

Introduced species may cause harm to native fish populations, which to design any conservative program to control the exotics an identification key is necessary. To find the morphological differences among the exotic Rhinogobius lindbergi and its sympatric congeners including the endemic Ponticla iranicus and the native Ponticla gorlap, a 15-landmark morphometric system was used to examine 90 specimens in Sefid River, in the Southern Caspian Sea basin. Univariate analysis of variance showed significant differences among the means of the three groups for 79 out of 105 standardized morphometric measurements. Principal component analysis ( $P C A)$ and canonical variates analysis $(C V A)$ confirmed the statistically significant difference among these species. The $C V A$ scatter plot showed that the 90 studied specimens grouped into three distinct areas with a degree of overlap between $P$. iranicus and $P$. gorlap. Clustering based on Euclidean distances among the groups of centroids using an UPGMA indicated segregation of the three species into two distinct clusters: P. iranicus and $P$. gorlap in one group and $R$. lindbergi in the other group. The exotic Rhinogobius can be distinguished from the sympatric gobies in Sefid River by short snout (vs. longer), deep body (vs. shallow), deeper head, stout body, and smaller ventral disc.

Keywords: Gobiidae, truss network system, geometric morphometric, landmark, Iran
ARTICLE INFO

\section{RESEARCH ARTICLE}

Received : 28.01.2019

Revised : : 16.04.2019

Accepted : :26.04.2019

Published : :25.12.2019

DOI:10.17216/LimnoFish.515636

* CORRESPONDING AUTHOR

mousavi-sabet@guilan.ac.ir

mosavii.h@gmail.com

Phone : +98 1344320895

How to Cite

Heidari A, Mousavi-Sabet H, Sattari M, Alavi-Yeganeh MS. 2019. Landmark-Based Morphological Differences Among the Exotic Rhinogobius lindbergi and Its Two Sympatric Gobies (Actinopterygii: Perciformes: Gobiidae) in Sefid River, in the Southern Caspian Sea Basin. LimnoFish. 5(3): 159-169. doi: 10.17216/LimnoFish.515636

\section{Introduction}

Invasive species are alien (non-native) organisms that have been introduced into an area outside of their natural range, establishing self-sustaining populations and spreading beyond their initial point of introduction, with deleterious impacts on the environment, economy and human health (Lymbery et al. 2014). Biological invasions are now considered a major environmental issue of public concern (Gozlan et al. 2010).

In Iran, there is an exotic goby, Rhinogobius lindbergi, which is reported from the Hari River basin (Coad and Abdoli 2000), Anzali Wetland in the
Caspian Sea basin (Abdoli et al. 2000), the Zarrineh River (Zarrinehrud) in Urmia Lake basin (Eagderi and Moradi 2017), the Namak Lake basin (Eagderi et al. 2017), and the Tigris River basin (Sadeghi et al. 2018, Mousavi-Sabet et al. 2019). However, among the above-mentioned basins, the Caspian Sea basin is the only water basin which has native gobies, too. The genus Ponticola, with five species is the native genus which its members live in tributaries of the Caspian Sea basin (in Iranian portion). Ponticola gorlap (Iljin 1949), P. syrman (Nordmann 1840), P. ratan (Nordmann 1840), P. cyrius (Kessler 1874) and $P$. iranicus Vasil'eva, Mousavi-Sabet and Vasil'ev, 
2015 (Vasil'eva et al. 1993; Miller 2003; Medvedev et al. 2013; Vasil'eva et al. 2015) are reported from the basin. Normally, the fishes of the family Gobiidae are usually less important commercially, therefore knowledge on their identification and biodiversity is far from being complete (Miller 2004; Neilson and Stepien 2009; Bogutskaya et al. 2013). Regarding problems in Gobiids identification, separating the exotic and native individuals/populations is not easy. Therefore, to design any conservative program, a practical identification key is strongly necessary. Preparing any key to identify fish species needs powerful analytical manners which the traditional and modern morphological analyzing methods are normally used for fish populations/species. As mentioned above, morphological characters are most important in the identification and taxonomy of fishes, and the only known facts about many fishes. In addition, understanding the function of a morphological structure is a stronghold for practical use in taxonomy and ecology too (Turan 2004; Yamamoto et al. 2006; Pollar et al. 2007). In addition to traditional method, in recent years, truss network system is increasingly used for morphometric measurements with the purpose of species and/or stock differentiation (Turan 2004; AnvariFar et al. 2011; Mousavi-Sabet et al. 2012; Mousavi-Sabet and Anvarifar 2013; Khataminejad et al. 2013; Kohestan-
Eskandari et al. 2013, 2014; Heidari et al. 2014). Also, geometric morphometrics $(G M)$, a quantitative approach to analysis shape, is widely applied to compare and determine shape variations of biological structures (Adams et al. 2004). Despite traditional approaches, in $G M$, data is obtained from the coordinates of landmark points (Adams et al. 2004; Rohlf 2005), which are morphological points of specimens that are of biological interest (Rohlf 2005).

The present study aimed to clarify the morphometric differences among the exotic $R$. lindbergi and its sympatric endemic $P$. iranicus and native $P$. gorlap in Sefid River, in the southern Caspian Sea basin.

\section{Material and Methods \\ Fish sampling}

The specimens were collected on August 2015 to May 2017 in Sefid River $\left(37^{\circ} 01.153^{\prime} \mathrm{N}, 49^{\circ} 37.985^{\prime} \mathrm{E}\right)$ from the southwestern Caspian Sea basin, Iran (Figure 1). Fishes were collected by electrofishing. The sampled fishes were photographed and then fixed in $10 \%$ formaldehyde at the sampling site and transported to the Laboratory for further studies. Identification was verified base on Vasil'eva et al. 1993, Miller 2003 and Vasil'eva et al. 2015 in the laboratory.

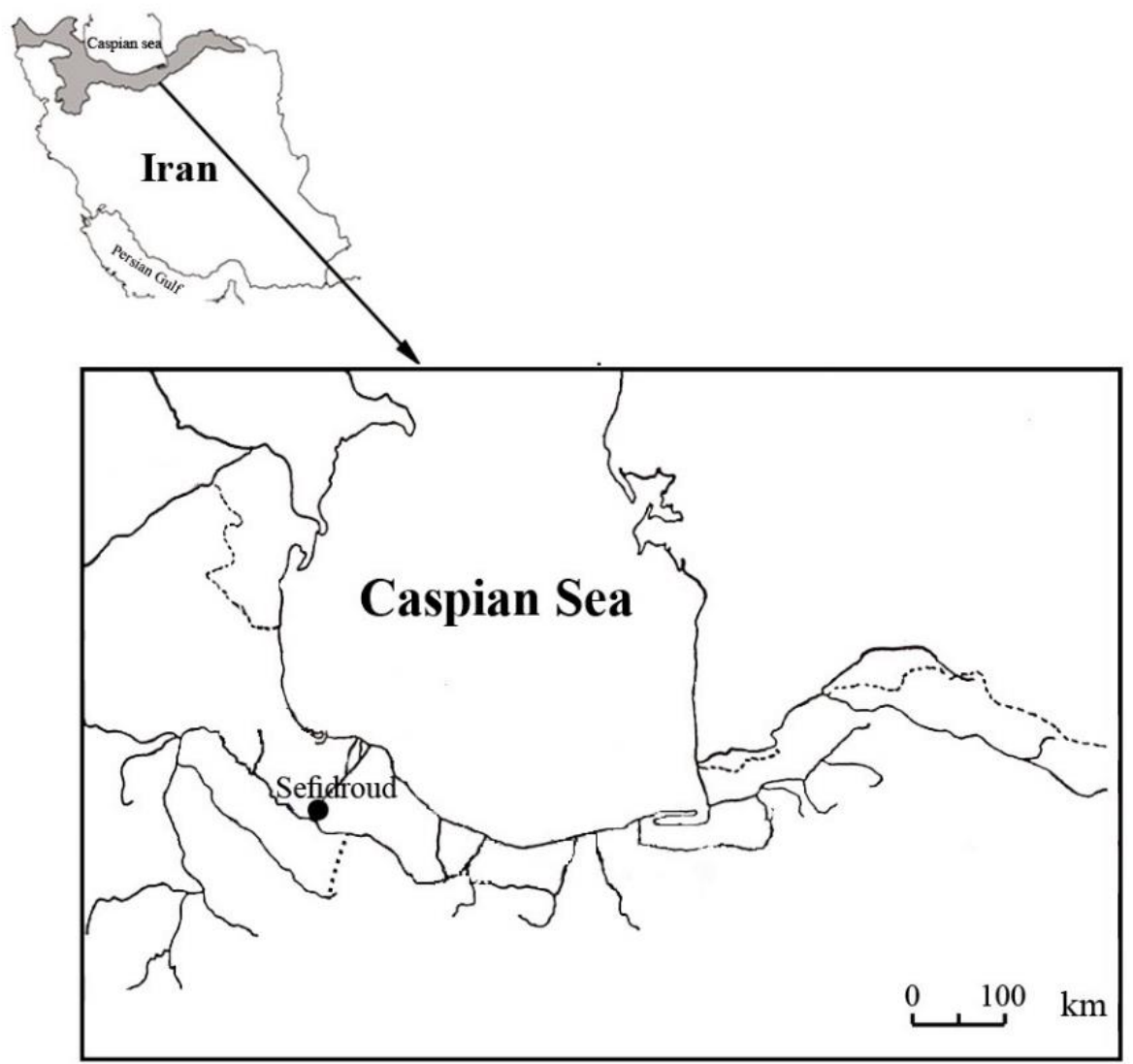

Figure 1. Map of the Iranian part of the southern Caspian Sea basin and location of Sefid River from the southern Caspian Sea basin. 


\section{Laboratory work}

In the laboratory, Standard Length $( \pm 1.0 \mathrm{~mm})$ and body weight $( \pm 0.001 \mathrm{~g})$ were recorded for each specimen. For specimens 105 distance measurements between 15 landmarks on the lateral side and 78 distance measurements were surveyed using the truss network system according to Bookstein (1991) with minor modifications for these species (Figure 2). Also, for specimens 44 and 28 distance measurements between 10 and 8 landmarks on ventral and dorsal views, respectively, were surveyed for investigation under and up sides shape variation. The fishes were placed on a white board with dorsal and anal fins held erect by pins. The left body profile of each fish was photographed with a 300-dpi, 32-bit color digital camera (Cybershot DSC-F505; Sony, Japan). Images were saved in jpg format and analyzed with TPSdig to coordinates of landmarks. All measurements transformed into linear distances by computer for subsequent analysis. After image capture, the fish was dissected to identify the sex of the specimen by macroscopic examination of the gonads. Gender was used as the class variable in ANOVA to test for the significant differences in the morphometric characters if any, between male and female specimens.

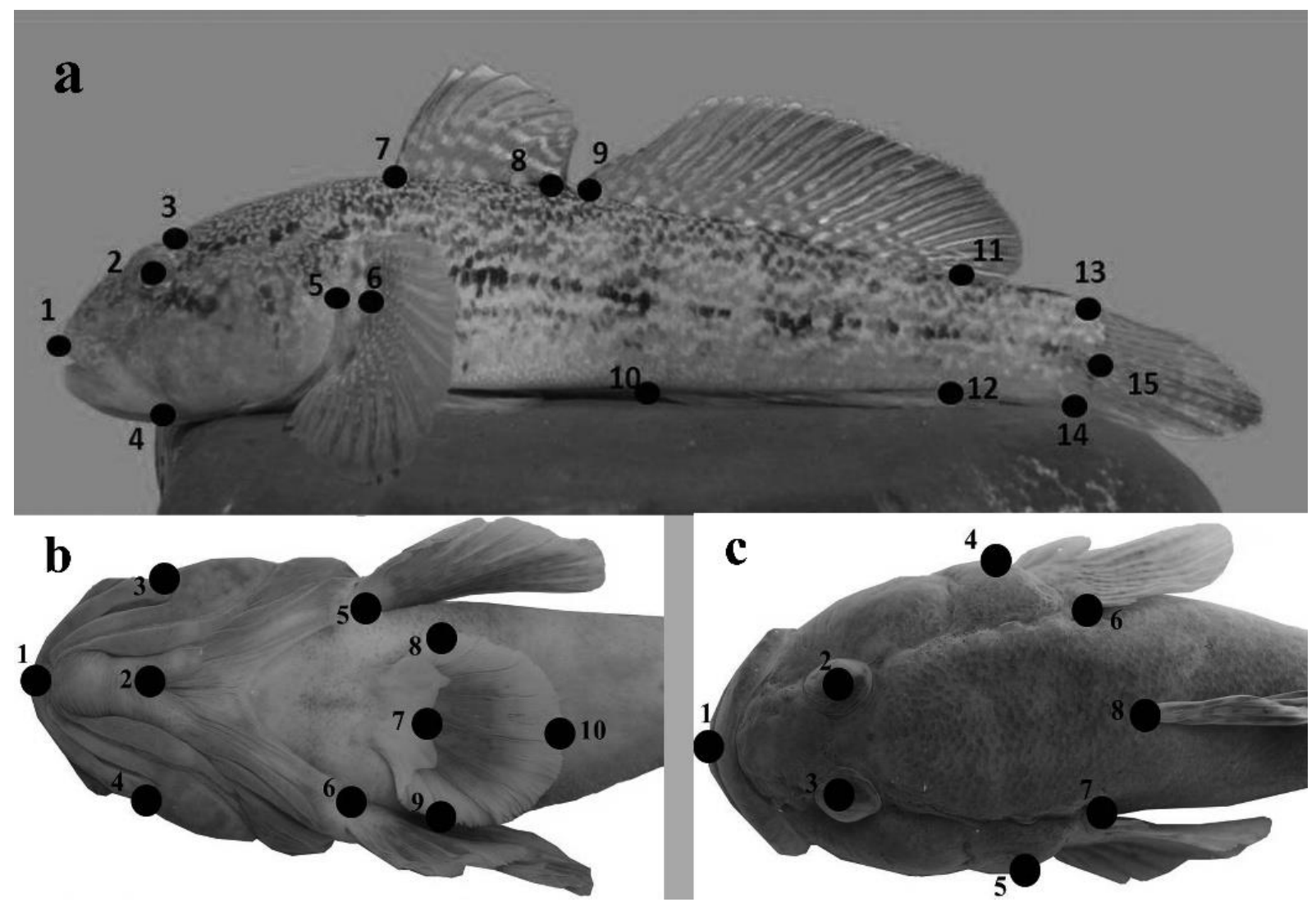

Figure 2. Locations of the landmarks on lateral (a), ventral (b) and dorsal (c) sides of the goby.

\section{Data analysis}

As variation should be attributed to body shape differences, and not related to the relative size of the fish, an allometric method (Elliott et al. 1995) was used to remove size-dependent variation in morphometric characters:

$$
M a d j=M\left(L_{s} / L_{0}\right)^{b}
$$

where $M$ is the original measurement, Madj the size adjusted measurement, $L_{0}$ the standard length of the fish, $L_{s}$ the overall mean of the standard length for all fish from all samples in each analysis, and $b$ was estimated for each character from the observed data as the slope of the regression of $\log M$ on $\log L_{0}$ using all fish in any group. The results derived from the allometric method were confirmed by testing the significance of the correlation between transformed variables and standard length (Mustafic et al. 2008).

Univariate analysis of variance (ANOVA) was performed for each morphometric character to evaluate the significant difference among the fish specimens (Bookstein 1991). Principal component analysis ( $P C A)$ and canonical variates analysis (CVA) were employed to discriminate these fishes from studied rivers. Statistical analyses for morphometric data were performed using the SPSS version 16 software package, past ver. 1.36, MorphoJ and Excel (Microsoft Office 2010).

\section{Results}

Descriptive data were examined for the mean and standard deviation $(S D)$ of length and weight in case 
of sampled specimens (Table 1). Although it is well known that the female and male specimens of the gobies have some morphological differences (Mousavi-Sabet et al. 2012; Vasil'eva et al. 2015), but the interaction between morphometric measurements used in this study by truss network system and sexes uses ANOVA analysis was not significant $(\mathrm{P}>0.05)$, demonstrating a negligible effect of sex on observed variations; hence, the data for both sexes were pooled for all subsequent analyses. There was no significant correlation between any of the transformed measured morphometric variables and standard length $(\mathrm{P}>0.05)$, indicating that size or allometric signature on the basic morphological data was accounted.

Table 1. Descriptive data [mean \pm SD standard length $(\mathrm{mm})$ and body weight $(\mathrm{g})]$ of goby specimens.

\begin{tabular}{lccccc}
\hline Species & $\mathrm{n}$ & \multicolumn{2}{c}{ Standard length $(\mathrm{mm})$} & \multicolumn{2}{c}{ Body weight $(\mathrm{g})$} \\
\hline & & Min-max & Mean \pm SD & Min-Max & Mean \pm SD \\
\cline { 3 - 6 } R. lindbergi & 30 & $35.71-112.87$ & $70.55 \pm 21.85$ & $1.15-34.90$ & $10.25 \pm 9.30$ \\
$P$. iranicus & 30 & $53.33-139.92$ & $74.23 \pm 23.64$ & $3.77-51.61$ & $12.86 \pm 11.85$ \\
$P$. gorlap & 30 & $20.80-111.95$ & $55.30 \pm 20.80$ & $1.00-33.05$ & $5.81 \pm 8.11$ \\
\hline
\end{tabular}

Table 2. The results of ANOVA for morphometric measurements of goby specimens in Sefid River from the southern Caspian Sea basin.

\begin{tabular}{|c|c|c|c|c|c|c|c|c|c|c|c|}
\hline Characters & $\mathrm{F}$ & $\mathrm{P}$ & Characters & $\mathrm{F}$ & $\mathrm{P}$ & Characters & $\mathrm{F}$ & $\mathrm{P}$ & Characters & $\mathrm{F}$ & $\mathrm{P}$ \\
\hline $1-2$ & 11.75 & 0.00 & $3-4$ & 2.22 & 0.09 & $5-10$ & 1.41 & 0.24 & $8-13$ & 9.10 & 0.00 \\
\hline $1-3$ & 15.13 & 0.00 & $3-5$ & 0.28 & 0.84 & $5-11$ & 2.49 & 0.06 & $8-14$ & 8.92 & 0.00 \\
\hline $1-4$ & 6.19 & 0.00 & $3-6$ & 2.61 & 0.05 & $5-12$ & 4.14 & 0.00 & $8-15$ & 12.88 & 0.00 \\
\hline $1-5$ & 11.20 & 0.00 & $3-7$ & 4.22 & 0.00 & $5-13$ & 9.28 & 0.00 & $9-10$ & 23.10 & 0.00 \\
\hline $1-6$ & 9.66 & 0.00 & $3-8$ & 3.15 & 0.03 & $5-14$ & 4.11 & 0.00 & $9-11$ & 4.51 & 0.00 \\
\hline $1-7$ & 17.67 & 0.00 & $3-9$ & 3.33 & 0.02 & $5-15$ & 8.44 & 0.00 & $9-12$ & 4.09 & 0.00 \\
\hline $1-8$ & 18.66 & 0.00 & $3-10$ & 5.08 & 0.00 & $6-7$ & 1.79 & 0.15 & $9-13$ & 7.72 & 0.00 \\
\hline $1-9$ & 5.79 & 0.00 & $3-11$ & 5.54 & 0.00 & $6-8$ & 2.58 & 0.07 & $9-14$ & 6.35 & 0.00 \\
\hline $1-10$ & 9.46 & 0.00 & $3-12$ & 13.98 & 0.00 & $6-9$ & 4.60 & 0.00 & $9-15$ & 9.77 & 0.00 \\
\hline $1-11$ & 11.26 & 0.00 & $3-13$ & 8.46 & 0.00 & $6-10$ & 0.59 & 0.62 & $10-11$ & 0.22 & 0.88 \\
\hline $1-12$ & 23.86 & 0.00 & $3-14$ & 11.94 & 0.00 & $6-11$ & 1.80 & 0.15 & $10-12$ & 8.29 & 0.00 \\
\hline $1-13$ & 7.02 & 0.00 & $3-15$ & 8.72 & 0.00 & $6-12$ & 0.99 & 0.40 & $10-13$ & 7.65 & 0.00 \\
\hline $1-14$ & 8.40 & 0.00 & $4-5$ & 10.95 & 0.00 & $6-13$ & 14.05 & 0.00 & $10-14$ & 2.80 & 0.04 \\
\hline $1-15$ & 5.30 & 0.00 & $4-6$ & 9.92 & 0.00 & $6-14$ & 7.77 & 0.00 & $10-15$ & 9.37 & 0.00 \\
\hline $2-3$ & 8.76 & 0.00 & $4-7$ & 4.92 & 0.00 & $6-15$ & 12.78 & 0.00 & $11-12$ & 16.89 & 0.00 \\
\hline $2-4$ & 3.56 & 0.02 & $4-8$ & 4.27 & 0.00 & $7-8$ & 0.89 & 0.45 & $11-13$ & 10.85 & 0.00 \\
\hline $2-5$ & 4.85 & 0.00 & $4-9$ & 1.03 & 0.38 & $7-9$ & 7.28 & 0.00 & $11-14$ & 4.80 & 0.00 \\
\hline $2-6$ & 6.17 & 0.00 & $4-10$ & 4.71 & 0.00 & $7-10$ & 13.71 & 0.00 & $11-15$ & 19.42 & 0.00 \\
\hline $2-7$ & 9.57 & 0.00 & 4-11 & 6.94 & 0.00 & $7-11$ & 2.91 & 0.04 & $12-13$ & 16.96 & 0.00 \\
\hline $2-8$ & 4.99 & 0.00 & $4-12$ & 13.23 & 0.00 & $7-12$ & 1.13 & 0.34 & $12-14$ & 9.06 & 0.00 \\
\hline $2-9$ & 2.21 & 0.09 & $4-13$ & 0.67 & 0.57 & $7-13$ & 10.02 & 0.00 & $12-15$ & 18.95 & 0.00 \\
\hline $2-10$ & 4.44 & 0.00 & $4-14$ & 0.76 & 0.52 & $7-14$ & 11.32 & 0.00 & $13-14$ & 1.81 & 0.15 \\
\hline $2-11$ & 3.33 & 0.02 & $4-15$ & 0.38 & 0.77 & $7-15$ & 20.63 & 0.00 & $13-15$ & 1.42 & 0.24 \\
\hline $2-12$ & 20.26 & 0.00 & $5-6$ & 14.46 & 0.00 & $8-9$ & 2.30 & 0.08 & $14-15$ & 7.78 & 0.00 \\
\hline $2-13$ & 7.70 & 0.00 & $5-7$ & 1.34 & 0.26 & $8-10$ & 19.13 & 0.00 & & & \\
\hline $2-14$ & 2.12 & 0.10 & $5-8$ & 1.48 & 0.22 & $8-11$ & 7.15 & 0.00 & & & \\
\hline $2-15$ & 1.97 & 0.12 & $5-9$ & 2.46 & 0.07 & $8-12$ & 3.74 & 0.02 & & & \\
\hline
\end{tabular}

Statistically significant differences in goby specimens were observed in 79 morphometric characters out of 105 studied. Of these 79 characters, 72 characters were found to be highly significant $(\mathrm{P} \leq 0.01)$ and were used further for multivariate analysis (Table 2). The value of Kaiser-Meier-Olkin coefficient $(K M O)$ for the overall matrix is 0.721 for goby specimens and Bartlett's Test of sphericity is significant $(\mathrm{P} \leq 0.01)$. The results of $K M O$ and Bartlett's suggest that the sampled data is appropriate to proceed with a factor analysis procedure.
In order to determine which morphometric measurement affected populations differentiates mostly, the contributions of variables to principal components $(P C)$ were examined. The $P C A$ of 72 morphometric measurements for goby specimens extracted 12 factors with eigenvalues $>1$, explaining $93.91 \%$ of the variance (Table 3). Of these, the first explained $28.37 \%$ and the second $16.35 \%$ of the variance. The most significant weightings on $P C \mathrm{I}$ were from 1-5, 1-6, 5-15, 2-6, 2-5, 6-15, 6-9, 4-6, 45, 6-13, 6-14, 5-13, 1-14, 5-14, 1-4, 1-13, 1-11, 1-12, 
1-2, 5-12, 1-10, 1-8, 1-3, 1-7, 1-9 and on PC II were from 1-12, 12-15, 9-12, 12-13, 12-14, 3-12, 2-12, 10 $12,5-12,4-12$ and 3-14.

Canonical variates analysis confirmed the significant difference among the goby specimens.
The scores of the two canonical variables for each river revealed that goby specimens grouped into three species while there was a relativity high degree of overlap between $P$. iranicus and $P$. gorlap (Figure 3).

Table 3. Eigen values, percentage of variance and percentage of the cumulative variance of morphometric measurements for goby specimens in Sefid River from the southern Caspian Sea basin.

\begin{tabular}{lccc}
\hline Factor & Eigenvalues & Percentage of variance & Percentage of cumulative variance \\
\hline 1 & 20.141 & 28.367 & 28.367 \\
2 & 11.606 & 16.347 & 44.714 \\
3 & 8.061 & 11.354 & 56.068 \\
4 & 6.906 & 9.727 & 65.795 \\
5 & 4.550 & 6.408 & 72.203 \\
6 & 4.242 & 5.974 & 78.178 \\
7 & 2.754 & 3.879 & 82.056 \\
8 & 2.447 & 3.447 & 85.503 \\
9 & 2.097 & 2.953 & 88.456 \\
10 & 1.478 & 2.082 & 90.538 \\
11 & 1.350 & 1.901 & 92.439 \\
12 & 1.041 & 1.466 & 93.905 \\
\hline
\end{tabular}

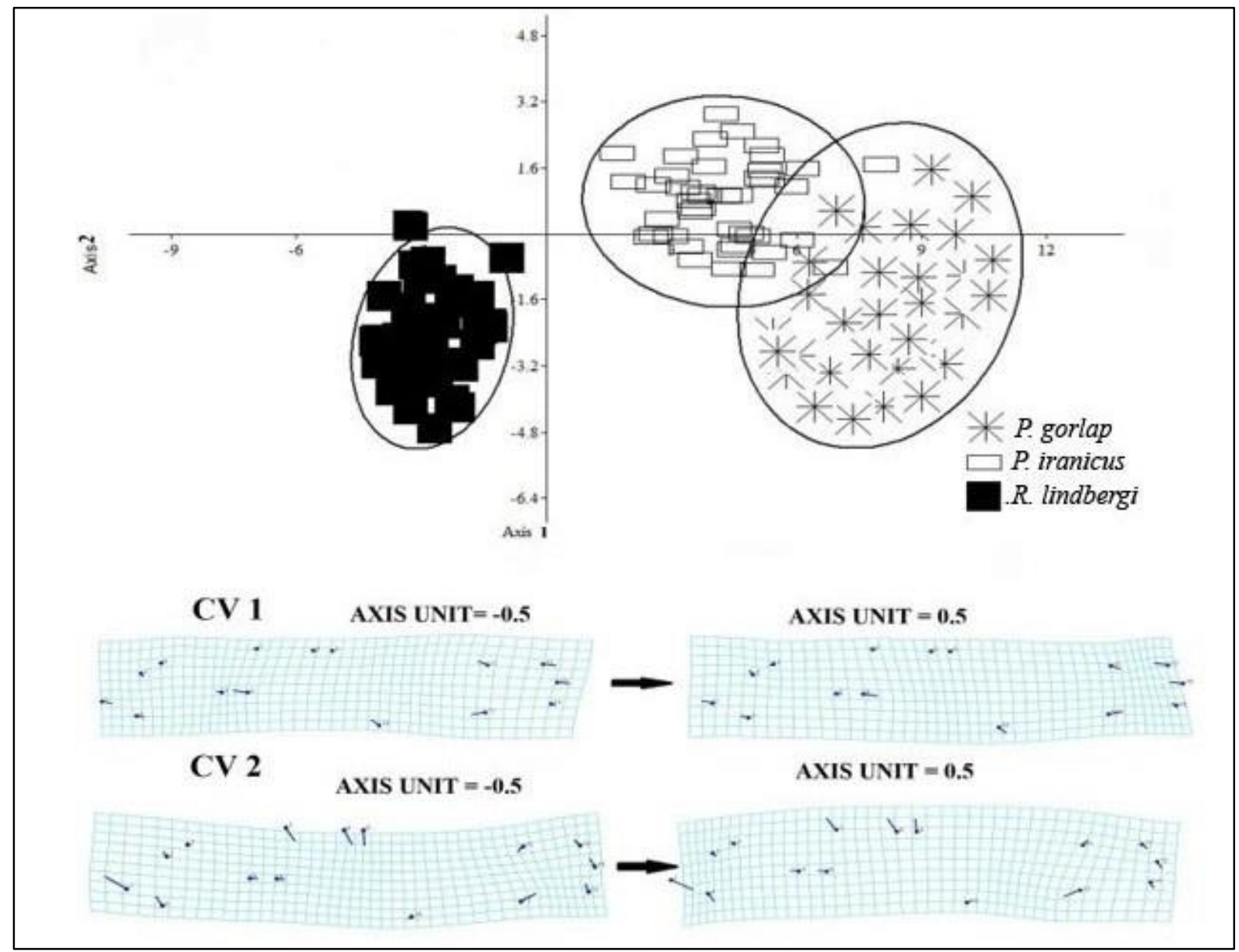

Figure 3. Scatterplot of standardized canonical variates functions 1 (CV1) and 2 (CV2) for morphometric characteristics of goby specimens

The Wilks' lambda tests indicated differences between fishes when their morphometric measurements were compared by means of discriminant analysis. In this test all functions were highly significant $(\mathrm{P} \leq 0.01)$. The histogram of discriminant functions for pairwise groups in goby specimens is shown in Figure 4. 

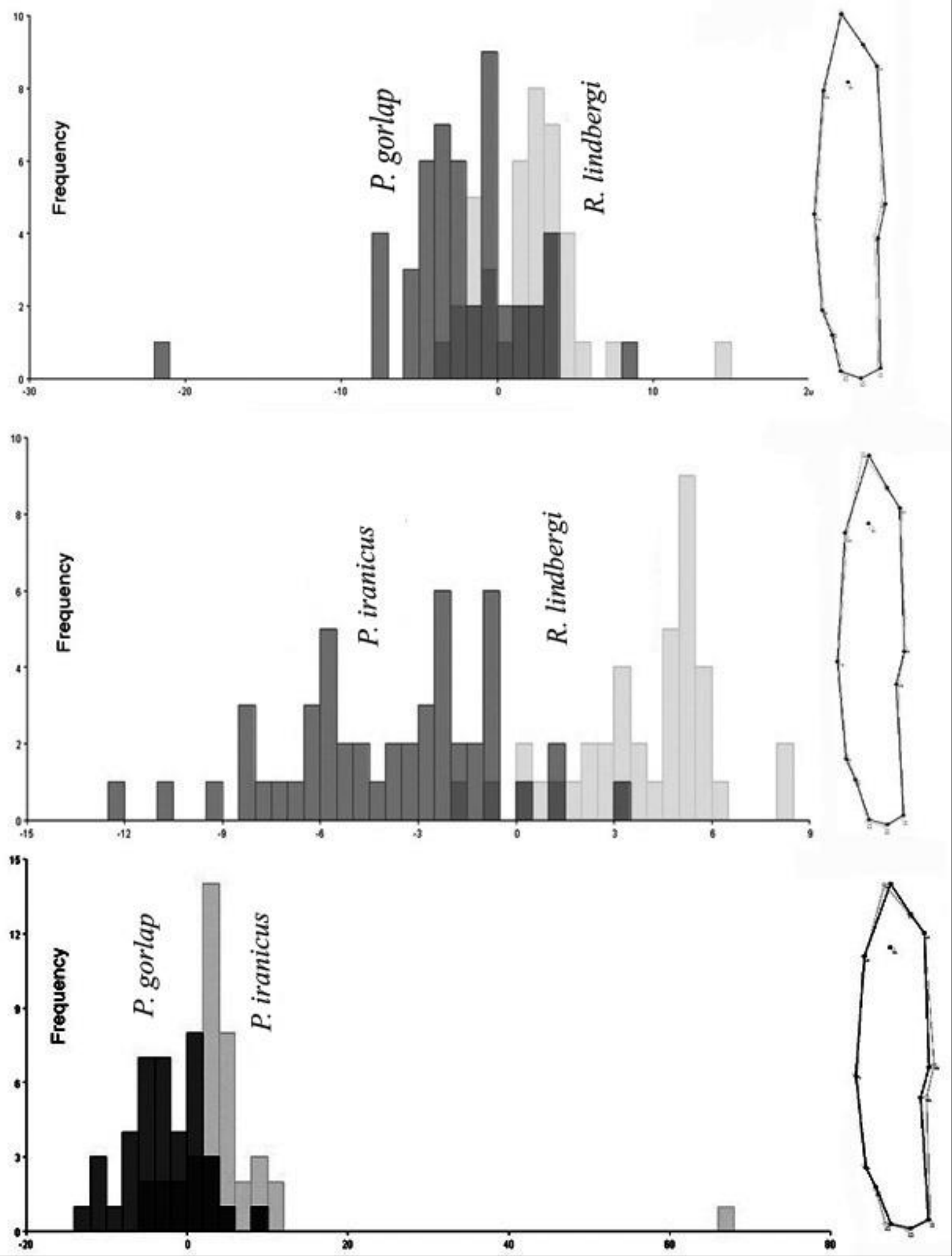

Figure 4. Histogram of discriminate analysis (DA) functions for pair wise competitions' of gobies (left). Shape differences on the extremities of each river (right).

Body shape differences show a longer snout, shallow body and head depths, and elongated body for $P$. gorlap and $P$. iranicus, vs. relatively short snout, high body and head depths and stout body for $R$. lindbergi. Also, underside and upside shape variation analysis show a longer snout and disc for $P$. gorlap and $P$. iranicus, vs. relatively short snout and disc and high body for R. lindbergi (Figure 5).

The dendrogram derived from the cluster analysis of Euclidean distances among groups 
of centroids showed that the three populations of gobies segregated from each other into two distinct clusters, $P$. gorlap and

$P$. iranicus appeared in one cluster while $R$. lindbergi belonged to the other clusters (Figure 6).

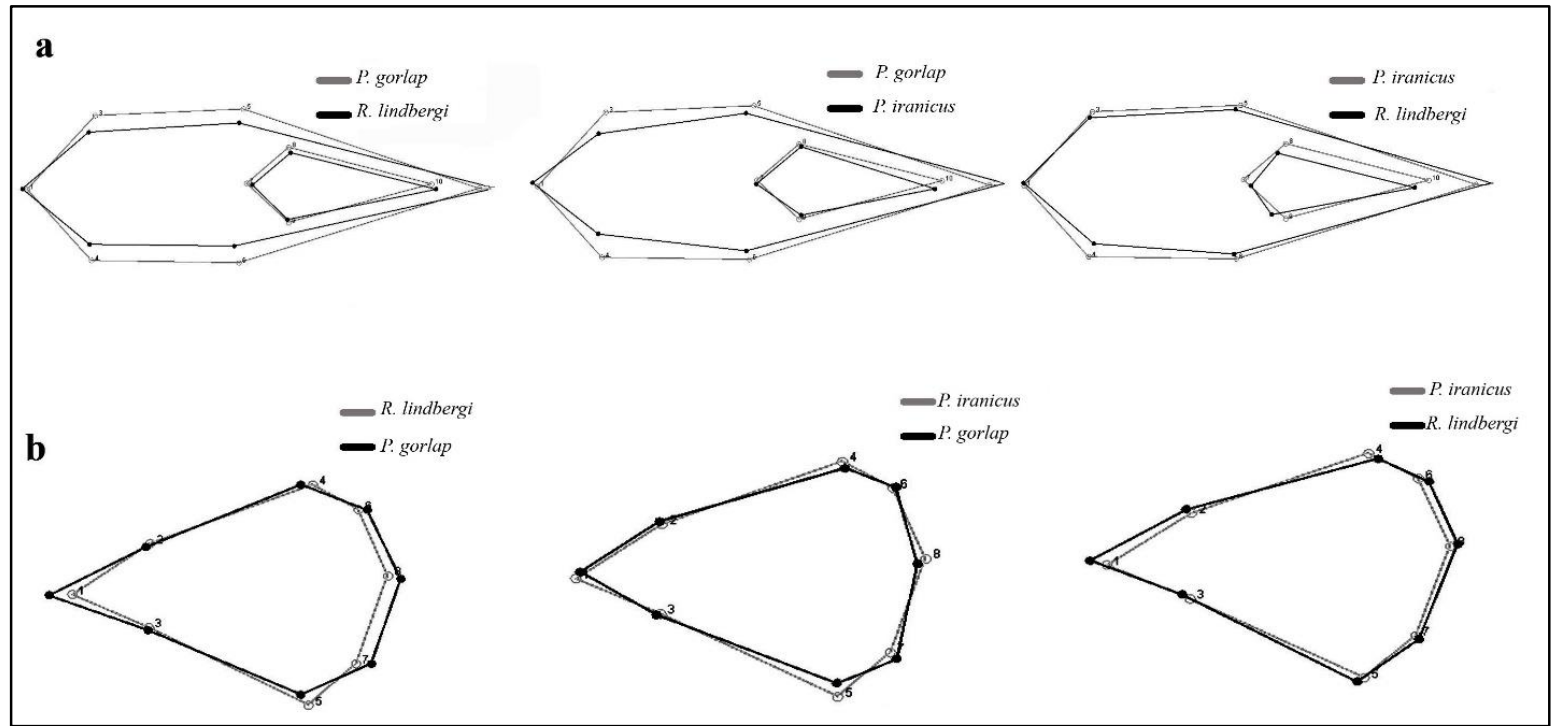

Figure 5. Underside and upside shape variation analysis of gobies in Sefid River from the southern Caspian Sea basin. (a) Ventral view (b) dorsal view.

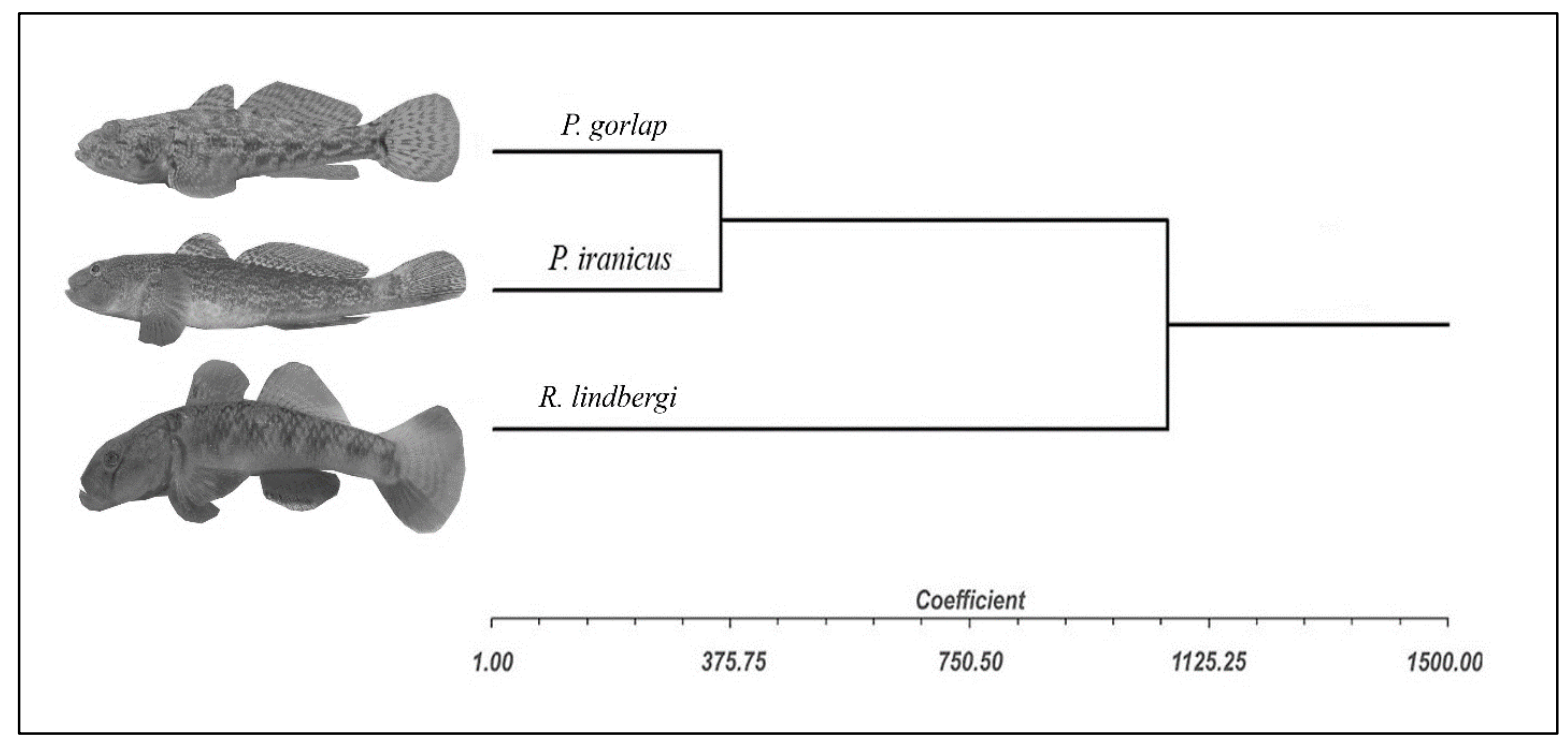

Figure 6. Dendrogram derived from cluster analyses of morphometric measurements on the basis of Euclidean distance for gobies in Sefid River from the Southern Caspian Sea. Mean shape of species in the relation of consensus shape of the species are also represented.

\section{Discussion}

The results of the multivariate analysis demonstrated that the three examined species are correctly separated from each other, which the two Ponticola (P. iranicus and P. gorlap) are classified as one clade and the Rhinogobius in the other clade. It is well known that both studied genera, Rhinogobius and Ponticola, are clearly distinct groups morphologically, and as the Ponticola are larger species than the Rhinogobius, they can be easily distinguished if the Ponticola is in its maximum range size. Despite these differences, separating small Ponticola specimens in the same size as Rhinogobius is not so easy or sometimes is unrecognizable by morphological characters. Therefore, the obtained results of the present study provide helpful identification key to separate them from each other. The results for the ANOVA analysis showed that 79 out of 105 transformed morphometric measurements were significantly different in these groups of Gobies living in the southern Caspian Sea basin, which demonstrates a high phenotypic variation among them. The PCA showed morphological segregation of the studied fishes based 
on the characters head shape, pre-dorsal, pre-anal distances, pre-orbital and post-orbital distances, body length, body depth, caudal peduncle depth, caudal peduncle length, dorsal and anal fins origin and caudal fin origin for gobies. Body shape differences for these fishes shows a longer snout, shallow body and head, and elongated body for $P$. iranicus and $P$. gorlap, vs. relatively short snout, deeper body and head and stout body for $R$. lindbergi, for general appearance see Figure 7.
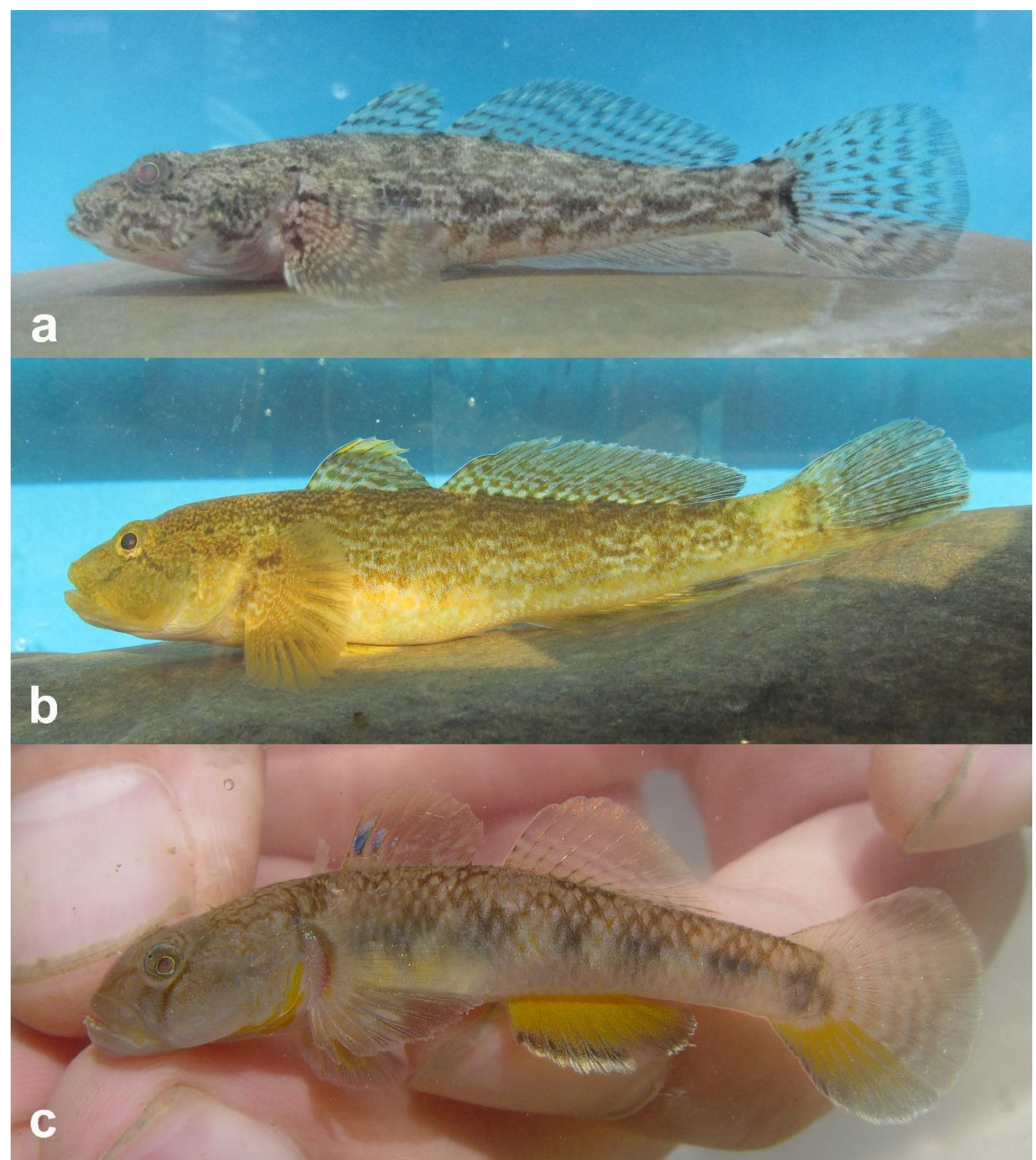

Figure 7. Ponticola gorlap (a), Ponticola iranicus (b) and Rhinogobius lindbergi (c).

CVA could be a useful method to distinguish different species of the same genus or different stocks of the same species, with respect to stock management programs (Bookstein 1991; Buj et al. 2008; Torres et al. 2010; AnvariFar et al. 2011; Heidari et al. 2013; Heidari et al. 2014). The results of $C V A$ obtained in the present study indicated the relative segregation among three species of gobies in the studied areas. This was confirmed by plotted $C V 1$ and $C V 2$ scores for each sample that showed 90 specimens grouped into three distinct areas with a degree of overlap between $P$. iranicus and $P$. gorlap. The morphological differences may be solely related to body shape variation and not to size effects which 
were successfully accounted for by allometric transformation. Literature shows that factor of size account more than $80 \%$ of variation among a set of variables in morphometric studies. On the other hand, factor of size plays a predominant role in morphometric analysis and makes result in erroneous status if it cannot be removed in statistical analyses of data (Bookstein 1991). In the present study, size effect was removed successfully by the allometric transformation, so any significant differences indicated by the ANOVA and multivariate analysis, are caused by the body shape variation.

The causes of morphological differences between species are often quite difficult to explain (McLaughlin and Grant 1994; Cadrin and Friedland 1999; Pakkasmaa and Piironen 2000; Cadrin 2000; Vatandoust et al. 2014a; Vatandoust et al. 2014b; Vatandoust et al. 2015; Paknejad et al. 2014). It has been suggested that the morphological characteristics of fish are determined by an interaction between genetic and environmental factors (Pinheiro et al. 2005). The phenotypic variability may not necessarily reflect population differentiation at the molecular level (Turan 2004; Yamamoto et al. 2006; Pollar et al. 2007; Eschmeyer and Fong 2011).

The present findings revealed the potential power of the landmark-based methods for the identification of goby specimens. The present study provides basic information about the differences of Ponticola species and the exotic $R$. lindbergi in Sefid River from the southern Caspian Sea basin and it suggests that observed morphological variation should be considered in stock management programs and commercial exploitation of these species as an ornamental fish in the aquarium trade.

\section{References}

Abdoli A, Coad BW, Naderi M. 2000. First record of Rhinogobius similis, Gill 1895 in Iran. Iran J Fish Sci. 9: 73-76.

Adams DC, Rohlf FJ, Slice DE. 2004. Geometric morphometrics: ten years of progress following the revolution. Ital J Zool. 71(1):5-16. doi: 10.1080/11250000409356545

AnvariFar H, Khyabani A, Farahmand H, Vatandoust S, AnvariFar H, Jahageerdar S. 2011. Detection of morphometric differentiation between isolated up- and downstream populations of siah mahi (Capoeta capoeta gracilis) (Pisces: Cyprinidae) in the Tajan River (Iran). Hydrobiologia. 673(1):41-52. doi: 10.1007/s10750-011-0748-7

Bogutskaâ NG, [Bogutskaya, NG.], Kiâško, PV. [Kijashko, PV.], Naseka AM, Orlova MI. 2013. Opredelitelryb i bespozvonočnyh Kaspijskogo mora. T. 1. Ryby i mollûski [Identification keys for fish and invertebrates of the Caspian Sea. V. 1. Fishes and mollusks.] Sankt-Peterburg-Moskva: KMK Scientific Press 244 p. [In Russian with English summary.]
Bookstein FL. 1991. Morphometric tools for landmark data. Cambridge, UK: Cambridge University Press $512 \mathrm{p}$.

Buj I, Podnar M, Mrakovcic M, Caleta M, Mustafic P, Zanella D. 2008. Morphological and genetic diversity of Sabanejewia balcanica in Croatia. Folia Zool. 57:100-110.

Cadrin SX, Friedland KD. 1999. The utility of image processing techniques for morphometric analysis and stock identification. Fish Res. 43(1-3):129-139 doi: 10.1016/S0165-7836(99)00070-3

Cadrin SX. 2000. Advances in morphometric analysis of fish stock structure. Rev Fish Biol Fish. 10(1): 91-112. doi: 10.1023/A:1008939104413

Coad BW, Abdoli A. 2000. Rhinogobius cf. similis Gill, 1859, a goby new to the fish fauna of Iran and the problem of alien invasions. Zool Middle East. 20(1):55-59. doi: 10.1080/09397140.2000.10637812

Eagderi S, Jouladeh-Roudbar A, Soleymani A, Hosseinpour T. 2017. The first record of Rhinogobius similis Gill, 1859 from the Namak basin, Iran. Shil. 5(1):39-46.

Eagderi S, Moradi M. 2017. Range extension of the lake goby Rhinogobius smilis Gill, 1859 (Teleostei: Gobidae) to the Urmia Lake basin in northwest Iran. Biharean Biologist. 11(2):123-125.

Elliott NG, Haskard K, Koslow JA. 1995. Morphometric analysis of orange roughly (Hoplostethus atianticus) off the continental slope of Southern Australia. J Fish Biol. 46(2):202-220. doi: 10.1111/j.1095-8649.1995.tb05962.x

Eschmeyer WN, Fong JD. 2011. Animal biodiversity: An outline of higher level classification and survey of taxonomic richness. Zootaxa. 3148:26-38.

Gozlan RE, Britton JR, Cowx I, Copp GH. 2010. Current knowledge on non-native freshwater fish introductions. J Fish Biol. 76(4):751-786. doi: 10.1111/j.1095-8649.2010.02566.x

Heidari A, Mousavi-Sabet H, Khoshkholgh M, Esmaeili HR, Eagderi S. 2013. The impact of Manjil and Tarik dams (Sefid River, southern Caspian Sea basin) on morphological traits of Siah Mahi Capoeta gracilis (Pisces: Cyprinidae). International Journal of Aquatic Biology. 1(4):195-201. doi: 10.22034/ijab.v1i4.72

Heidari A, Khoshkholgh M, Mousavi-Sabet H. 2014. Tracing the effects of Sefidrud dams on Capoeta gracilis (Cyprinidae) populations using truss distances in southern Caspian Sea basin. Iranian Journal of Ichthyology. 1(2): 106-113. doi: $10.22034 /$ iji.v1i2.45

Khataminejad S, Mousavi-Sabet H, Sattari M, Vatandoust S, Eagderi S. 2013. A comparative study on body shape of the genus Alburnus (Rafinesque, 1820) in Iran, using geometric morphometric analysis. Caspian Journal of Environmental. 11:205-215.

Kohestan-Eskandari S, AnvariFar H, Mousavi-Sabet H. 2013. Detection of Morphometric Differentiation of Liza aurata (Pisces: Mugilidae) in Southeastern of the Caspian Sea, Iran. Our Nature. 11(2):126-137. 
doi: 10.3126/on.v11i2.9595

Kohestan-Eskandari S, AnvariFar H, Mousavi-Sabet H, Yousefi M, Khanzade M. 2014. A morphology-based hypothesis for homeward migration success and population differentiation in the anadromous kutum Rutilus kutum (Pisces: Cyprinidae) along the southern Caspian Sea, Iran. Folia Zool. 63(3):151-160. doi: 10.25225/fozo.v63.i3.a2.2014

Lymbery AJ, Morine M, Kanani HJ, Beatty S.J, Morgan DJ. 2014. Co-invaders: The effects of alien parasites on native hosts. International Journal for Parasitology: Parasites and Wildlife. 3(2):171-177. doi: 10.1016/j.ijppaw.2014.04.002

McLaughlin RL, Grant JWA. 1994. Morphological and behavioral differences among recently-emerged brook charr, Salvelinus fontinalis, foraging in slow-vs. fast-running water. Environ Biol Fish. 39(3):289-300. doi: 10.1007/BF00005130

Medvedev DA, Sorokin PA, Vasil'ev VP, Chernova NV, Vasil'eva ED. 2013. Reconstruction of phylogenetic relations of Ponto-Caspian gobies (Gobiidae, Perciformes) based on mitochondrial genome variation and some problems of their taxonomy. Journal of Ichthyology. 53(9):702-712. doi: 10.1134/S0032945213060064

Miller PJ. 2003. The freshwater fishes of Europe. V. 8/I. Mugilidae, Atherinidae, Atherinopsidae, Blenniidae, Odontobutidae, Gobiidae 1. Wiebelsheim, Germany: Aula-Verlag $404 \mathrm{p}$.

Miller PJ. 2004. The freshwater fishes of Europe. V. 8/II. Gobiidae 2. Wiebelsheim, Germany: Aula-Verlag $450 \mathrm{p}$.

Mousavi-Sabet H, Yerli SV, Vatandoust S, Ozeren S.C, Moradkhani Z. 2012. Cobitis keyvani sp. nova - a new species of spinedloach from South of the Caspian Sea Basin (Teleostei: Cobitidae). Turk J Fish Aquat Sc. 12:7-13. doi: 10.4194/1303-2712-v12_1_02

Mousavi-Sabet H, Anvarifar H. 2013. Landmark-based morphometric variation between Cobitis keyvani and Cobitis faridpaki (Pisces: Cobitidae), with new habitat for $C$. faridpaki in the southern Caspian Sea basin. Folia Zool. 62(3):167-175. doi: 10.25225/fozo.v62.i3.a1.2013

Mousavi-Sabet H, Amouei M, Salehi M, Salehi-Farsani A, Heidari A. 2019. Range extension and a new locality for the lake goby Rhinogobius lindbergi Berg, 1933 in the upper Tigris River drainage, Iran. FishTaxa. 4(1):9-12.

Mustafic P, Marcic Z, Duplic A, Mrakovcic M, Caleta M, Zanella D. 2008. A new loach species of the genus Cobitis in Croatia. Folia Zool. 57(1-2):4-9.

Neilson ME, Stepien CA. 2009. Escape from the PontoCaspian: Evolution and biogeography of an endemic goby species flock (Benthophilinae: Gobiidae: Teleostei). Mol Phylogenet Evol. 52(1):84-102. doi: 10.1016/j.ympev.2008.12.023

Pakkasmaa S, Piironen J. 2000. Water velocity shapes juvenile salmonids. Evol Ecol. 14(8):721-730. doi: 10.1023/A:1011691810801

Paknejad S, Heidari A, Mousavi-Sabet H. 2014. Morphological variation of shad fish Alosa brashnicowi (Teleostei, Clupeidae) populations along the southern Caspian Sea coasts, using a truss system. International Journal of Aquatic Biology. 2(6):330-336.

Pinheiro A, Teixeira CM, Rego AL, Marques JF, Cabral HN. 2005. Genetic and morphological variation of Solea lascaris (Risso, 1810) along the Portuguese coast. Fish Res. 73(1-2):67-78. doi: 10.1016/j.fishres.2005.01.004

Pollar M, Jaroensutasinee M, Jaroensutasinee K. 2007. Morphometric analysis of Tor tambroides by stepwise discriminant and neural network analysis. International Journal of Bioengineering and Life Sciences. 1(9):106-110.

Rohlf FJ. 2005. TPS Dig, version 2.04. State University of New York, Department of Ecology and Evolution, Stony Brook.

Sadeghi R, Esmaeili HR, Zarei F, Esmaeili A, Abbasi K. 2018. The taxonomic status of an introduced freshwater goby of the genus Rhinogobius to Iran (Teleostei: Gobiidae). Zool Middle East. 65(1):51-58. doi: 10.1080/09397140.2018.1540149

Torres RGA, Gonzalez PS, Pena SE. 2010. Anatomical, histological and ultraestructural description of the gills and liver of the Tilapia (Oreochromis niloticus). Int J Morphol. 28(3):703-712. doi: $10.4067 /$ S0717-95022010000300008

Turan C, Erguden D, Gurlek M, Basusta N, Turan. 2004. Morphometric structuring of the anchovy (Engraulis encrasicolus L.) in the Black, Aegean and northeastern Mediterranean Seas. Turk J Vet Anim Sci. 28(5):865-871.

Vasil'eva ED, Vasil'ev VP, Pinčuk VI, [Pinchuk VI.] 1993. Kraniologičes kijanaliz byčkovpodroda Ponticola Iljin, 1927. III. Sravnitel'no-morfologič eskoeiss ledovanie Neogobiuskessleri, $N$. ratan i dopolnitel nyesvedeniapo $N$. syrman $\mathrm{v}$ svazi s diagnostikoj i obëmompodroda Ponticola. [Craniological analysis on gobies from the subgenus Ponticolalljin, 1927. III. Comparative morphological investigation of Neogobius kessleri, $N$. ratan and additional data on $N$. syrman in relation with diagnostic and structure of the subgenus Ponticola.] Voprosy Ichtiologii. 33(5):609-617. [In Russian.]

Vasil'eva ED, Mousavi-Sabet H, Vasil'ev VP. 2015. Ponticola iranicus sp. nov. (Actinopterygii: Perciformes: Gobiidae) from the Caspian Sea basin. Acta Ichthyol Piscat. 45(2):189-197. doi: 10.3750/AIP2015.45.2.09

Vatandoust S, Abdoli A, Anvarifar H, Mousavi-Sabet H. 2014a. Morphometric and meristic characteristics and morphological differentiation among five populations of Brown Trout Salmo trutta fario (Pisces: Salmonidae) along the southern Caspian Sea basin. European Journal of Zoological Research. 3(2):56-65.

Vatandoust S, Nejati M, Anvarifar H, Mousavi-Sabet H. 2014b. Morphological Differentiation of Vimba persa (Pisces: Cyprinidae) along the southern Caspian Sea Basin, Iran. European Journal of Zoological Research. 3(2):94-102.

Vatandoust S, Mousavi-Sabet H, Razeghi-Mansour M, AnvariFar H, Heidari A. 2015. Morphometric 
variation of the endangered Caspian lamprey, Caspiomyzon wagneri (Pisces: Petromyzontidae), from migrating stocks of two rivers along the southern Caspian Sea. Zool Stud. 56:1-9.

doi: 10.1186/s40555-015-0133-8
Yamamoto S, Maekawa K, Tamate T, Koizumi I, Hasegawa K, Kubota H. 2006. Genetic evaluation of translocation in artificially isolated populations of white-spotted Charr (Salvelinus leucomaenis). Fish Res. 78(2-3):352-358.

doi: 10.1016/j.fishres.2005.11.011 